ACCEPTED MANUSCRIPT

\title{
Anionic Quantum Dots reveal actin-microridges in zebrafish epidermis
}

To cite this article before publication: Valeria Sigot et al 2020 Methods Appl. Fluoresc. in press https://doi.org/10.1088/2050-6120/ab9124

\section{Manuscript version: Accepted Manuscript}

Accepted Manuscript is "the version of the article accepted for publication including all changes made as a result of the peer review process, and which may also include the addition to the article by IOP Publishing of a header, an article ID, a cover sheet and/or an 'Accepted Manuscript' watermark, but excluding any other editing, typesetting or other changes made by IOP Publishing and/or its licensors"

This Accepted Manuscript is @ 2020 IOP Publishing Ltd.

During the embargo period (the 12 month period from the publication of the Version of Record of this article), the Accepted Manuscript is fully protected by copyright and cannot be reused or reposted elsewhere.

As the Version of Record of this article is going to be / has been published on a subscription basis, this Accepted Manuscript is available for reuse under a CC BY-NC-ND 3.0 licence after the 12 month embargo period.

After the embargo period, everyone is permitted to use copy and redistribute this article for non-commercial purposes only, provided that they adhere to all the terms of the licence https://creativecommons.org/licences/by-nc-nd/3.0

Although reasonable endeavours have been taken to obtain all necessary permissions from third parties to include their copyrighted content within this article, their full citation and copyright line may not be present in this Accepted Manuscript version. Before using any content from this article, please refer to the Version of Record on IOPscience once published for full citation and copyright details, as permissions will likely be required. All third party content is fully copyright protected, unless specifically stated otherwise in the figure caption in the Version of Record.

View the article online for updates and enhancements. 
1 Anionic Quantum Dots reveal actin-microridges in zebrafish epidermis

2 3

4 39 Valeria Sigot ${ }^{1,2}$, Paulo E. Cabral Filho ${ }^{3}$, María F. Sampedro ${ }^{1,2}$, Beate S. Santos ${ }^{4}$, Adriana Fontes ${ }^{3}$ *

${ }^{1}$ Laboratorio de Microscopía Aplicada a Estudios Moleculares y Celulares, Facultad de Ingeniería, Universidad Nacional de Entre Ríos (UNER), Oro Verde, Argentina.

${ }^{2}$ Instituto de Investigación y Desarrollo en Bioingeniería y Bioinformática (IBB-CONICET-UNER), dependiente de CCT-Santa Fe, Argentina.

${ }^{3}$ Departamento de Biofísica e Radiobiologia, Universidade Federal de Pernambuco (UFPE), Recife, Brazil.

${ }^{4}$ Departamento de Ciências Farmacêuticas, Universidade Federal de Pernambuco (UFPE), Recife, Brazil.

\section{${ }^{*}$ Corresponding authors:}

Valeria Sigot:

Email: vsigot@ingenieria.uner.edu.ar

Postal address: Ruta 11, km 10, Facultad de Ingeniería, E3100XAD, Oro Verde, Entre Ríos, Argentina.

Tel +543434975100

\section{Adriana Fontes:}

Email: adri-fontes@uol.com.br

Postal address: Av Prof Moraes Rego, S/N, Departamento de Biofísica e Radiobiologia, CCB, UFPE, 50670-901, Recife, Pernambuco, Brazil

Tel +55 812126781

\section{Abstract}

Enhancement of the aqueous solubility and functionalization of CdTe-QDs (Quantum Dots) via surface modifications have made them suitable to be used as specific probes for cell imaging. Applications for targeting cell surfaces have been widely demonstrated in vitro but their use in animal models is not trivial.

Here, we reported the interaction of mercaptosuccinic-coated (MSA) CdTe-QDs with the epidermis of living and Carnoy-fixed zebrafish embryos.

QDs concentrate along adherent junctions and reveal the characteristic pattern of actin microridges at the apical surface of the enveloping layer. In our study, labeling with anionic QDs is attained within minutes at nanomolar concentrations in whole mounted Carnoy-fixed zebrafish embryos, providing a faster approach compared with immunodetection or standard Phalloidin staining of actin for visualization by fluorescence microscopy.

40 Keywords: actin-microridges, anionic quantum dots, zebrafish epidermis 


\section{1}

2

3

4

5

6

7

8

9

10

11

\section{Introduction}

Nanotechnology has opened new possibilities to understand a variety of biological processes through the development of innovative nanosystems and techniques [1,2]. Since the '90s, Quantum Dots (QDs) have attracted increasing attention as an alternative nano-tool for life science, being applied in studies in vitro and in vivo, in biosensing, to monitor their interactions with cells or between biological molecules [1]. The development of hydrophilic QDs, coated with a chemically active surface for functionalization, has made these nanoparticles suitable as specific probes for imaging living biological systems as well as for other fluorescence-based bioassays [3]. QDs have already been conjugated with several classes of biomolecules, such as lectins and antibodies. These conjugates allowed, for example, to study cancer and microbial cell biology, taking advantage of the exceptional resistance to photobleaching suitable for long-term imaging [4,5]. Moreover, the blinking property of QDs has also been explored in super-resolution microscopy [6]. Studies in biological models in vivo and in vitro have been also conducted to assess the potential hazards of these materials [7][3].

The zebrafish is an ideal transparent model to apply new fluorescent probes for imaging. Despite the variety of functionalized QDs, their application as in vivo fluorescent probes in zebrafish remains scarce, and it has been limited to label vascular and neuronal systems $[8,9]$. This is in part due to physical restriction for targeting specific organs and tissues in adults or developed embryos.

Technically, the incorporation of nanoparticles or biomolecules in zebrafish is usually carried out by microinjection through the chorion at the one-cell stage [10], or in the heart ventricle after $24 \mathrm{hpf}$ (hours post fertilization) [9]. At later stages, uptake of non-targeted QDs is most likely to occur via the gastrointestinal tract [11]. In any case, the final fate of the nanoparticles largely depends on their size, shape, and surface chemistry [12,13].

Zebrafish epidermis has been used as a tissue model for epithelial studies mainly due to its structural and functional homology to human skin $[8,14,15]$. In particular, zebrafish develops a bilayered epidermis within $24 \mathrm{hpf}$, constituted by the epidermal basal layer (EBL) and the enveloping layer $(E V L)$. After three weeks, the bilayered epidermis becomes further stratified [16,17]. During epidermis morphogenesis, the apical zone of the EVL extends membrane projections known as microridges [1820]. Recent microscopy studies support the idea that the patterned microridges organize the surface glycocalyx and protective mucus layer [17,21]. Besides, studies of microridge dynamics suggest that these patterned structures could act as a stable reserve of pre-polymerized F-actin readily available for cellular remodeling during epithelial wound healing processes [22].

In the present paper, we explored the interaction of exogenously added mercaptosucciniccoated CdTe QDs with the embryonic bilayered epidermis of living and Carnoy-fixed zebrafish embryos.

40 


\section{Experimental}

\subsection{Quantum dots synthesis and optical characterization}

CdTe QDs were synthesized in an aqueous colloidal dispersion stabilized with 3-mercaptosuccinic acid (MSA).The nanocrystal average diameter and suspension concentration were estimated by UVVis spectroscopy following procedures described by Yu et al [23] and Dagtepe et al. [24]. Detailed calculations and characterization were carried out according to Tenório et al [5] with minor modifications. Briefly, QDs were prepared by the addition of $\mathrm{Te}^{2-}$ in a $\mathrm{Cd}\left(\mathrm{ClO}_{4}\right)_{2}$ solution at $\mathrm{pH}>10$ in the presence of MSA as the stabilizing agent in a 5:1:6 molar ratio of Cd:Te:MSA, respectively. All reagents used were acquired from Sigma-Aldrich. QDs were optically characterized by absorption (UV-Vis 1800 - Shimadzu) and emission (LS 55 - PerkinElmer, at $\lambda_{\text {exc }}=488 \mathrm{~nm}$ ) spectroscopies.

\subsection{Zebrafish husbandry}

A zebrafish (Danio rerio) strain of T/AB genetic background was used. Male and female adults were maintained at $28^{\circ} \mathrm{C}, \mathrm{pH} 7.0$ - 8.0, on a $14 \mathrm{~h}$ light $/ 10 \mathrm{~h}$ dark cycle. Adults and embryos were handled according to the ARRIVE guidelines and to the national guidelines from the Advisory Committee on Ethics of the Facultad de Bioquímica y Ciencias Biológicas de la Universidad Nacional del Litoral, Santa Fe, Argentina (Res. 229 and 388/2006).

After breeding, laid eggs were collected and maintained at $28{ }^{\circ} \mathrm{C}$. Then, embryos and larvae were staged according to Kimmel et al. [25]. About 20 to 25 embryos were collected at 24, 31, and 48 hpf, then dechorionated and sedated with $0.01 \%$ buffered tricaine methanesulfonate (MS-222, SigmaAldrich). Embryos were then subjected to Carnoy fixation for immunodetection of E-cadh and $\beta$-actin as well as to study the interaction with negatively charged CdTe QDs. Moreover, 20 live embryos of 10 and 24 - 28 hpf were dechorionated before incubation with QDs at $28^{\circ} \mathrm{C}$.

\subsection{Immunodetection of E-cadh and $\beta$-actin}

Embryos were fixed in toto in Carnoy solution (60\% ethanol, 30\% chloroform, $10 \%$ glacial acetic acid) overnight at $4^{\circ} \mathrm{C}$. Briefly, embryos were washed in phosphate-buffered saline $(\mathrm{PBS}, \mathrm{pH}$ 7.4) and permeabilized in 1\% Triton X-100/PBS for $1.5 \mathrm{~h}$. Then, they were washed in PBS and incubated in normal goat serum (Vector Laboratories) for $45 \mathrm{~min}$, followed by overnight incubation with primary antibody anti-E-cadherin, clone 36 mouse IgG2a, 610181, Transduction Laboratories) or anti$\beta$-actin (monoclonal antibody, 8224, Abcam) at $4{ }^{\circ} \mathrm{C}$. After three washes in PBS, embryos were incubated for $2 \mathrm{~h}$ with a secondary goat anti-mouse IgG-FITC antibody (Sigma-Aldrich, F8771) at 25 ${ }^{\circ} \mathrm{C}$ in darkness under orbital shaking. Finally, they were rinsed in PBS and mounted in 50\% (v/v) glycerol-PBS for microscopy imaging. Embryos were also directly incubated with secondary antibody and normal goat serum as a negative control.

\subsection{Incubation of live and fixed embryos with QDs}

An aliquot of MSA-CdTe QDs suspension at $\mathrm{pH} 10$ was adjusted to $\mathrm{pH} 8.0$ with an aqueous solution of MSA ( $4.9 \% \mathrm{w} / \mathrm{v})$. Then the suspension was rinsed using 10-kDa filters (GE Healthcare) and resuspended in PBS, or embryo medium, before incubation. 


\section{Results and discussion}

\subsection{QDs optical characterization}

Red-emitting QDs were selected for simultaneous/detection with green-emitting FITC-conjugated antibodies. The emission wavelength of QDs was tuned by controlling the size of the growing crystals during synthesis. Fluorescence spectrum of MSA-CdTe QDs aqueous suspension showed an intense emission peak at $630 \mathrm{~nm}$ and a full width at a half maximum (FWHM) of about $53 \mathrm{~nm}$ (Fig. 1). Moreover, based on the first absorption maximum peak at $582 \mathrm{~nm}$, an average particle size of approximately $3.4 \mathrm{~nm}$ was estimated. The concentration was estimated to be $c a .7 \mu \mathrm{M}$ by absorption measurements using the molar extinction coefficient for CdTe QDs.

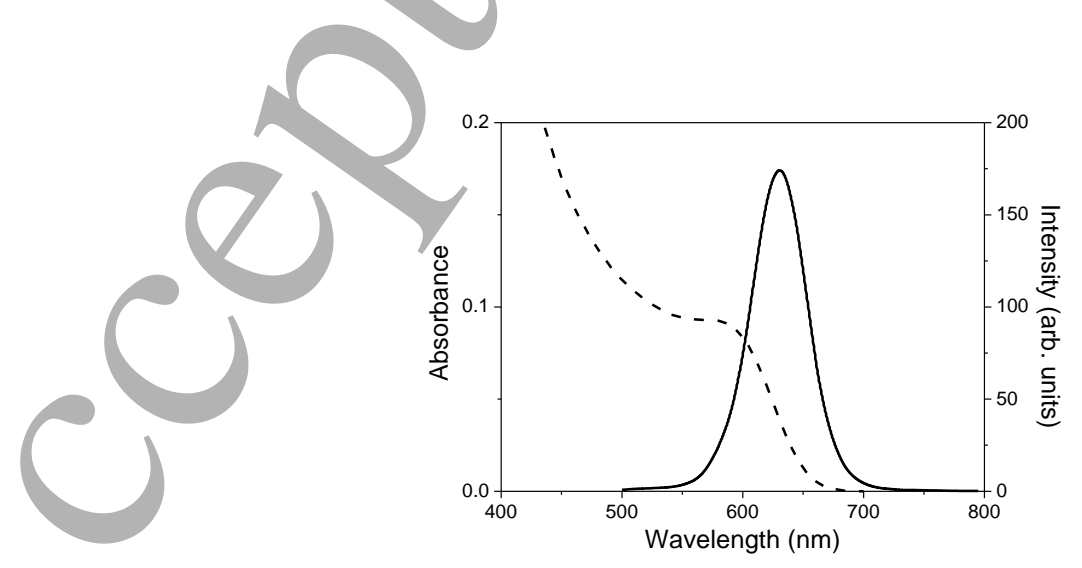

Living embryos were manually dechorionated and incubated in water $\mathrm{pH} 6.5-7.0$ for $2 \mathrm{~h}$ at 28 ${ }^{\circ} \mathrm{C}$ with $0.7 \mu \mathrm{M}$ QDs suspension. All treated embryos were rinsed and mounted in $1 \%$ low melting acose and covered with $0.01 \%$ tricaine solution for image acquition.

We treated two groups of fixed and permeabilized embryos (3-5 embryos per $1 \mathrm{~mL}$-polypropylene tube). The first one was incubated only with QDs (50 $\mu \mathrm{L}, 0.7 \mu \mathrm{M}$ final concentration), for 5, 10 and 30 min at $25^{\circ} \mathrm{C}$. The second group was incubated with QDs suspension under the same conditions, after immunofluorescence detection (section 2.3). Then, embryos were thoroughly washed in PBS $\mathrm{pH} 7.4$ and mounted in 50\% (v/v) PBS-glycerol for at least 2 hours before image acquisition.

At the selected working concentration QDs labeling showed a high signal to noise ratio

\subsection{Microscope settings and image acquisition} equipped with a digital camera CMOS-ORCA-Flash 2.8 (Hamamatsu) and commanded by Olympus CellSens software v. 1.13.

FITC and QDs signals were collected with ET - EGFP (FITC/Cy2, Chroma) and ET - DSRed (TRITC/Cy3, Chroma) filter sets respectively. Lamp power was set at $6 \%$ and sampling in xy was $0.182 \mu \mathrm{m}$ with z-step every $0.33 \mu \mathrm{m}$. At least 20 slices were collected to cover the epidermis bilayer thickness $(\sim 6.6 \mu \mathrm{m})$. Epidermis analysis from z-stacks was performed using FIJI v. 3.0.

Figure 1. Absorption (dashed line) and emission (full line) spectra of MSA-CdTe QDs, $\lambda_{\mathrm{exc}}=488 \mathrm{~nm}$. 


\subsection{QDs interaction with live and fixed zebrafish embryos}

The interaction of QDs with cell surfaces in biological systems has been discussed in length. Several factors influence this interaction, such as; size, shape and/or surface functional group and the biological system under investigation [26,27].

We sought to study the interaction of anionic red-emitting MSA-CdTeQDs with the epidermis of living zebrafish embryos after exogenous addition at two developmental stages, first during gastrulation and epidermis morphogenesis from $10 \mathrm{hpf}$ and after $24 \mathrm{hpf}$, when the EVL covers the whole embryo and a bilayered epidermis is established. When QDs were incubated with embryos during gastrulation and allowed to develop up to $24 \mathrm{hpf}$, they were detected as scattered dots in the trunk (Fig. 2a) or head. In contrast, in embryos exposed to QDs for $2 \mathrm{~h}$ at $24 \mathrm{hpf}$, no labeling was attained. Only after generating a local physical injury of the epidermis, QDs immediately labeled the wounded area (Fig. 2b). QDs labeling localized to cell membranes and more faintly the cytoplasm of cells around the site of injury. This may be explained by the disruption of the protective mucus and of the negatively charged glycocalyx which may prevent the anionic MSA CdTe-QDs from binding to the intact epidermis in vivo [28].

In order to get access to the epidermal cells, embryos were fixed in Carnoy solution and permeabilized and then incubated with $0.7 \mu \mathrm{M}$ QDs solution for 5,10 and $30 \mathrm{~min}$ at $25^{\circ} \mathrm{C}$ (section 2.4). Carnoy solution has been described to preserve mucus [29] but its effect on the glycocalyx layer is not yet clear. Interestingly, we observed that within 5-10 minutes QDs labeled the cell membranes of the overlaying EVL, delineating cell-cell contacts and apical microridges (Fig. 2c-d). QDs labeling remained localized to microridges after extended incubation for 12 hours with $1.1 \mathrm{uM}$ QDs and did not penetrate beyond the EVL (Suppl. Information Fig. S1).
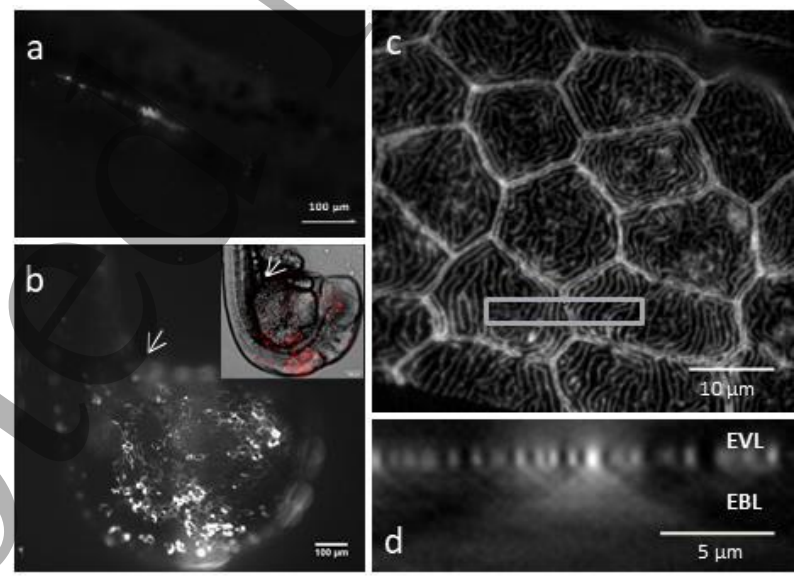

Figure 2. Exogenous addition of anionic MSA-CdTe QDs to live and fixed zebrafish embryos. a) Dispersed QDs were localized in the trunk of live embryos observed at $48 \mathrm{hpf}$ (arrowhead) after $2 \mathrm{~h}$ incubation with QDs at $28^{\circ} \mathrm{C}$. The arrow indicates autofluorescence from yolk extension. This image is a maximum intensity projection of 66 slices. b) Live embryo (24 hpf), incubated with QDs for $2 \mathrm{~h}$ was labeled only upon physical injury at the yolk (arrow). c) Carnoy-fixed embryos at $48 \mathrm{hpf}$ incubated with 31 thickness, $\sim 12 \mu \mathrm{m}$, only cells of the EVL were labeled. 


\section{1}

\subsection{QDs label cell-cell contacts at the EVL but not the EBL}

The embryonic epidermis is characterized by the expression of epithelial E-cadherin (E-cadh) outlining adherens junctions in both layers [30]. Based on the surface membrane labeling attained in fixed embryos with QDs, we analyzed whether the distribution of those nanoparticles correlates to that of Ecadh. Dual labeling was carried out by incubating embryos with QDs suspension after indirect lgGFITC antibody immunodetection of E-cadh. Analysis of 3D-stacks across the epidermis showed that QDs fluorescence colocalized with E-cadh-FITC staining in the EVL layer but not in the underlying basal layer, EBL (Fig 3c-d and Movie 1 in Suppl.Information).
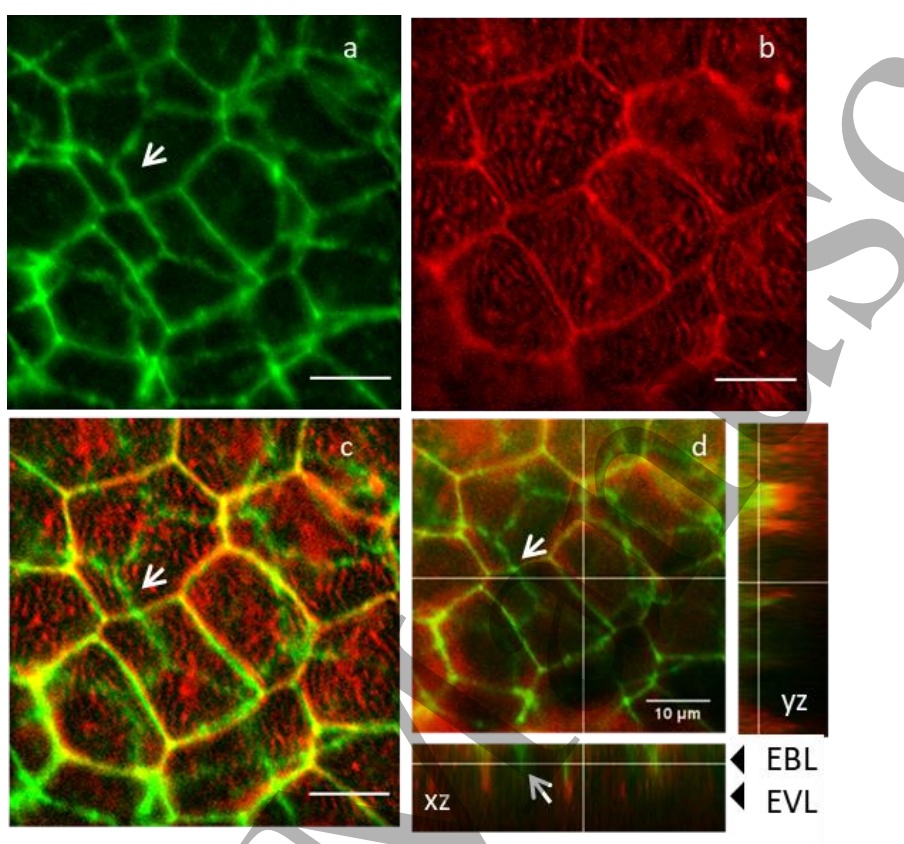

Figure 3. Dual labeling of membranes with QDs and E-cadh-lgG-FITC in embryos fixed at $24 \mathrm{hpf}$. a) E-cadh-IgG-FITC in the external EVL and underlying EBL (white arrow). b) Microridges labeled with red-emitting QDs on the EVL surface. c) QDs colocalize with E-cadh in EVL cells but are absent in the underlying EBL; d) Orthogonal views of 14 slices every $0.33 \mu \mathrm{m}$, covering $\sim 4.6 \mu \mathrm{m}$ of epidermis thickness. Fixed embryos incubated with QDs, five minutes at $25^{\circ} \mathrm{C}$, after immunostaining. Shown Images are contrast-enhanced maximum intensity z-projections. Green: FITC, Red: QDs em. 630 nm. Scale bar: $100 \mu \mathrm{m}$.

\subsection{QDs colocalize with actin in cell-cell contacts and in apical microridges}

Microridges are structurally constituted by filamentous actin and actin-binding proteins forming a highly dynamic network on the cell surface [20,22,31]. We then evaluated whether the observed QDs pattern correlated to that of F-actin. QDs colocalized with cortical actin in adherens junctions and with actin in apical microridges in fixed embryos of $48 \mathrm{hpf}$ (Fig.4). These observations are consistent with the filamentous form of actin in these structures shown by standard Phalloidin staining [22].

Ai-Xue et al., showed that F-actin can interact electrostatically with negatively charged lipids using surface plasmon resonance and electrochemical impedance spectroscopy[32]. Thus, it is conceivable that Carnoy fixation may reduce carboxylates, sulfates and the sialic acid content of the 

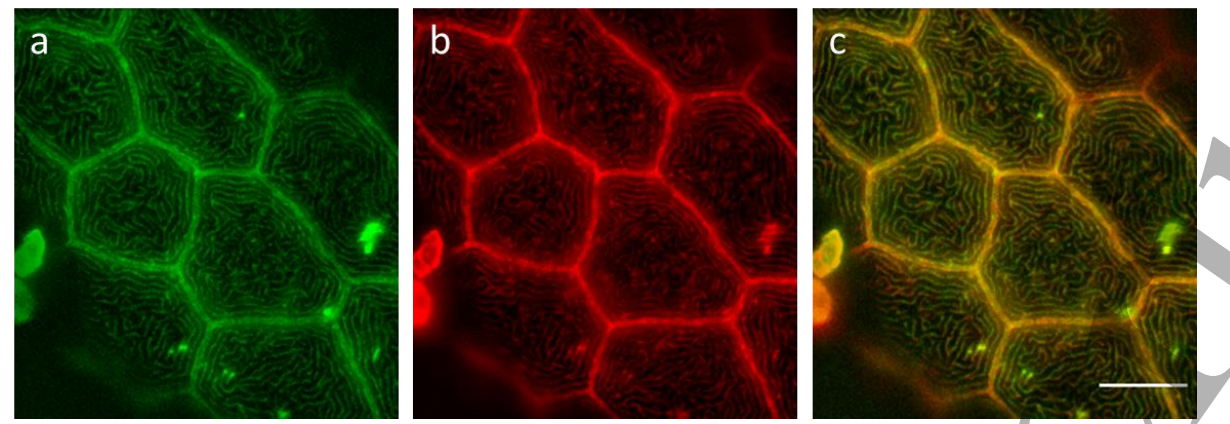

glycocalyx surface allowing MSA-CdTe QDs to interact with F-actin mediated by electrostatic forces. To our knowledge, this is the first description of microridges labeling with MSA-CdTe QDs as probes. 3

Figure 4. Dual labeling of microridges in peridermal cells of fixed embryos at $48 \mathrm{hpf}$. a) green channel showing indirect IgG-FITC F-actin labeling; b) red channel showing labeling with QDs; c) overlay of green and red channels showing colocalization of QDs and F-actin at the membranes but partial overlap in microridges. Fixed embryos incubated with QDs, five minutes at $25^{\circ} \mathrm{C}$ after immunostaining. Shown are maximum intensity z-projections. Scale bar: $10 \mu \mathrm{m}$.

Targeting the zebrafish epidermis with anionic QDs evidences that in vivo, the negatively charged glycocalyx and the protective mucus act as a first barrier, being impermeable to free nanoparticles. This was indeed evidenced after local injury of the epidermis and after fixation and permeabilization allowing for global membrane labeling of the whole embryo surface.

In zebrafish, actin microridges have been observed by gold standard Phalloidin staining [22] and by electron microscopy and live imaging [20] showing the overall arrangement of microridges as fingerprint-patterned structures on cell dorsal surfaces[14].To our knowledge, this is the first description of labeling actin in microridges with non-targeted anionic MSA-CdTe QDs in zebrafish embryos. The QDs labeling approach is intended for in toto labeling of zebrafish embryos and larvae fixed in Carnoy. Additional high-resolution microscopy studies should provide further evidence of the true interaction with actin in other conformations and structures.

Microridges are not restricted to fish tissue and are indeed found in various mammalian epithelial tissues.-Recently, these structures have been getting considerable attention due to their dynamic organization during normal development and the alterations of the patterned structure in several epithelial-derived cancer cell types in vitro and during wound healing [33].

\section{Conclusions}

We have demonstrated here that, non-targeted $4 \mathrm{~nm}$-sized anionic QDs proved suitable as a fluorescent probe for the identification of junctional actin in cell adhesions and the identification of $F$ actin supported microridges in the enveloping layer of zebrafish embryo epidermis.

QDs labeling was reproducible and specific for microridges structures, working from nano- to micromolar concentrations and for incubation times varying from less than $10 \mathrm{~min}$ to 12 hours. In particular, red-emitting QDs were suitable for simultaneous detection with green fluorescent probes being as well as spectrally distinctive from endogenous fluorescence emission from the yolk. 
The presented QDs labeling method is achieved within ten minutes at nanomolar concentrations being compatible with classical immunodetection protocols and less time-consuming than standard Phalloidin staining for F-actin.

Despite the ubiquitous presence of microridges in human epithelia, their role and relevance in the normal organization of the surface glycan layer are still poorly known. In addition, alterations of microridges patterns during the pathological transformation of epithelia have been long recognized, but not exploited as diagnostic or therapeutic markers.

Only in the last decade, microridges were studied at the molecular level by high-resolution fluorescence microscopy techniques. Our results indicate the potential of anionic QDs as fluorescent probes capable of providing new information about actin-microridges which may help to elucidate biological processes including normal epithelial morphogenesis and cancer progression.

\section{Acknowledgments}

The authors acknowledge the Brazilian agencies: Coordenação de Pessoal de Nível Superior (CAPES), Conselho Nacional de Desenvolvimento Científico e Tecnológico (CNPq), and Fundação de Amparo à Ciência e a Tecnologia do Estado de Pernambuco (FACEPE). This work is also linked to the National Institute of Photonics (INCT-INFo) and LARnano/UFPE. The authors also acknowledge the financial support from the National University of Entre Ríos, Argentina and the English language editing services provided by Prof. Diana Waigandt (Área de Asesoramiento Interdisciplinar - Facultad de Ingeniería - Universidad Nacional de Entre Ríos).

\section{Conflict of interests}

The authors have declared that no conflicting interests exist.

\section{References}

1. Wegner KD, Hildebrandt N. Quantum dots: bright and versatile in vitro and in vivo fluorescence imaging biosensors. Chem Soc Rev. 2015;44: 4792-4834. doi:10.1039/C4CS00532E

2. Pereira G, Monteiro C, Albuquerque G, Pereira M, Cabrera M, Cabral P, et al. (Bio)conjugation Strategies Applied to Fluorescent Semiconductor Quantum Dots. J Braz Chem Soc. 2019 [cited 13 Oct 2019]. doi:10.21577/0103-5053.20190163

3. Santos BS, Farias PMA, Fontes A. Semiconductor Quantum Dots for Biological Applications. Handbook of Self Assembled Semiconductor Nanostructures for Novel Devices in Photonics and Electronics. Elsevier; 2008. pp. 773-798. doi:10.1016/B978008046325-4.00026-8

4. Fontes A, Andrade C, Cabral Filho P, Tenorio D, Santos B, Beltrão E, et al. Evaluation of glycophenotype in breast cancer by quantum dot-lectin histochemistry. Int $\mathbf{J}$ 
5. Tenório DPLA, Andrade CG, Cabral Filho PE, Sabino CP, Kato IT, Carvalho LB, et al. CdTe quantum dots conjugated to concanavalin A as potential fluorescent molecular probes for saccharides detection in Candida albicans. J Photochem Photobiol B. 2015;142: 237-243. doi:10.1016/j.jphotobiol.2014.11.010

6. Fernández-Suárez M, Ting AY. Fluorescent probes for super-resolution imaging in living cells. Nat Rev Mol Cell Biol. 2008;9: 929-943. doi:10.1038/nrm2531

7. Yong K-T, Law W-C, Hu R, Ye L, Liu L, Swihart MT, et al. Nanotoxicity assessment of quantum dots: from cellular to primate studies. Chem Soc Rev. 2013;42: 1236-1250. doi:10.1039/C2CS35392J

8. Li Q, Frank M, Thisse CI, Thisse BV, Uitto J. Zebrafish: A Model System to Study Heritable Skin Diseases. J Invest Dermatol. 2011;131: 565-571. doi:10.1038/jid.2010.388

9. Son SW, Kim JH, Kim SH, Kim H, Chung A-Y, Choo JB, et al. Intravital imaging in zebrafish using quantum dots. Skin Res Technol. 2009;15: 157-160. doi:10.1111/j.16000846.2008.00341.x

10. Rosen JN, Sweeney MF, Mably JD. Microinjection of zebrafish embryos to analyze gene function. J Vis Exp JoVE. 2009; 1115. doi:10.3791/1115

11. van Pomeren M, Brun NR, Peijnenburg WJGM, Vijver MG. Exploring uptake and biodistribution of polystyrene (nano)particles in zebrafish embryos at different developmental stages. Aquat Toxicol. 2017;190:40-45. doi:10.1016/j.aquatox.2017.06.017

12. Alivisatos AP, Gu W, Larabell C. Quantum Dots as Cellular Probes. Annu Rev Biomed Eng. 2005;7: 55-76. doi:10.1146/annurev.bioeng.7.060804.100432

13. Williams Y. Surface Density of Charged Functional Groups on Quantum Dots Determines Their Intracellular Compartmentalization and Biocompatibility. 2017; 12.

14. Rakers S, Gebert M, Uppalapati S, Meyer W, Maderson P, Sell AF, et al. 'Fish matters': the relevance of fish skin biology to investigative dermatology. Exp Dermatol. 2010;19: 313-324. doi:10.1111/j.1600-0625.2009.01059.x

15. Eisenhoffer GT, Slattum G, Ruiz OE, Otsuna H, Bryan CD, Lopez J, et al. A toolbox to study epidermal cell types in zebrafish. J Cell Sci. 2017;130: 269-277. doi:10.1242/jcs.184341

16. Chang W-J, Hwang P-P. Development of zebrafish epidermis. Birth Defects Res Part C Embryo Today Rev. 2011;93: 205-214. doi:10.1002/bdrc.20215

17. Le Guellec D, Morvan-Dubois G, Sire J-Y. Skin development in bony fish with particular emphasis on collagen deposition in the dermis of the zebrafish (Danio rerio). Int J Dev Biol. 2003;48: 217-231.

18. Zalik SE, Lewandowski E, Kam Z, Geiger B. Cell adhesion and the actin cytoskeleton of the enveloping layer in the zebrafish embryo during epiboly. Biochem Cell Biol. 1999;77: $527-542$. 
19. Crawford BD, Henry CA, Clason TA, Becker AL, Hille MB. Activity and Distribution of Paxillin, Focal Adhesion Kinase, and Cadherin Indicate Cooperative Roles during Zebrafish Morphogenesis. Mol Biol Cell. 2003;14: 3065-3081. doi:10.1091/mbc.e02-080537

20. Lam P, Mangos S, Green JM, Reiser J, Huttenlocher A. In Vivo Imaging and Characterization of Actin Microridges. Weaver AM, editor. PLOS ONE. 2015;10: e0115639. doi:10.1371/journal.pone.0115639

21. Rakers S, Niklasson L, Steinhagen D, Kruse C, Schauber J, Sundell K, et al.' Antimicrobial Peptides (AMPs) from Fish Epidermis: Perspectives for Investigative Dermatology. J Invest Dermatol. 2013;133: 1140-1149. doi:10.1038/jid.2012.503

22. Sharma A, Anderson KI, Müller DJ. Actin microridges characterized by laser scanning confocal and atomic force microscopy. FEBS Lett. 2005;579: 2001-2008. doi:10.1016/j.febslet.2005.02.049

23. Yu WW, Qu L, Guo W, Peng X. Experimental Determination of the Extinction Coefficient of CdTe, CdSe, and CdS Nanocrystals. Chem Mater. 2003;15: 2854-2860. doi:10.1021/cm034081k

24. Dagtepe P, Chikan V, Jasinski J, Leppert VJ. Quantized Growth of CdTe Quantum Dots; Observation of Magic-Sized CdTe Quantum Dots. J Phys Chem C. 2007;111: 1497714983. doi:10.1021/jp072516b

25. Kimmel, C. B., Ballard, W. W., Kimmel, S. R., Ullmann, B. and Schilling, T. F. Stages of embryonic development of the zebrafish. Dev Dyn. 1995;203: 253-310. doi:10.1002/aja.1002030302

26. Filho P, Cabrera M, Cardoso A, Santana O, Geraldes C, Santos B, et al. Multimodal highly fluorescent-magnetic nanoplatform to target transferrin receptors in cancer cells. Biochim Biophys Acta BBA - Gen Subj. 2018. doi:10.1016/j.bbagen.2018.08.014

27. Jiang X-Y, Sarsons CD, Gomez-Garcia MJ, Cramb DT, Rinker KD, Childs SJ. Quantum dot interactions and flow effects in angiogenic zebrafish (Danio rerio) vessels and human endothelial cells. Nanomedicine Nanotechnol Biol Med. 2017;13: 999-1010. doi:10.1016/j.nano.2016.12.008

28. Baskin JM, Dehnert KW, Laughlin ST, Amacher SL, Bertozzi CR. Visualizing enveloping layer glycans during zebrafish early embryogenesis. Proc Natl Acad Sci. 2010;107: 10360-10365. doi:10.1073/pnas.0912081107

29. Johansson MEV, Hansson GC. Preservation of Mucus in Histological Sections, Immunostaining of Mucins in Fixed Tissue, and Localization of Bacteria with FISH. In: McGuckin MA, Thornton DJ, editors. Mucins. Totowa, NJ: Humana Press; 2012. pp. 229-235. doi:10.1007/978-1-61779-513-8_13

30. Sampedro MF, Izaguirre MF, Sigot V. E-cadherin expression pattern during zebrafish embryonic epidermis development. F1000Research. 2019;7: 1489. doi:10.12688/f1000research.15932.3 
31. Pinto CS, Khandekar A, Rajasekaran B, Kiesel P, Pigino G, Sonawane M. Microridges are apical projections formed of branched F-actin networks that organize the glycan layer. bioRxiv. 2018 [cited 21 Feb 2019]. doi:10.1101/442871

32. Ai-Xue LI,Xiao-Qiang CUI,Fan YANG,Xiu-Rong YANG. Interaction Between F-Actin and Negatively Charged Lipids Membrane. Chin J Anal Chem. 2009;37: 27-29.

33. Depasquale JA. Actin Microridges. Anat Rec. 2018;301: 2037-2050. doi:10.1002/ar.23965 